\title{
Translating Magic balancing art and science in the translation of Harry Potter
}

\author{
Matt Destruel
}

Literature is rightfully regarded as an art, but when translation enters the fray, it can require a somewhat scientific approach. Throw in a little bit of "Harry Potter" magic, and it can really become tricky. Translation is challenging, as it requires us to look not only at problems such as equivalence and the use of names, but also culture itself. Linguistic factors are also an issue, as a certain type of word might be abundant in the source language, but not very common in the target language. The role of the translator is therefore to distinguish what in a text is potentially translatable from what is fundamentally not. From there, one must walk the thin line between the art of translation - our personal hunches - and the science of translation - which is often too literal. In the case of J.K. Rowling, author of the Harry Potter book series, another difficulty arises. She has revealed herself as a wordsmith, not only with her writing skills, but also through her ability to coin and construct original words. Whether using terms from ancient mythologies, extinct languages or everyday life, her writing is known for an abundance of puns, linguistic jokes and other allusions that are mixed to create a brand new lexicon. Some examples include Harry Potter's school, Hogwarts, the magical sport, Quidditch, as well as an array of supernatural creatures such as Thestrals and Jobberknolls. This may be the reason why her books have caught the interest of the linguistics and translation studies communities; their richness and diversity make the possibilities nearly endless. Each name or word created comes with a baggage of undertones and veiled references that translators must track and recognize before they attempt to translate them. As an additional complication, the Harry Potter books were first thought to be children's literature, and only later attracted an older audience more prone to read between the lines and detect the hidden meanings of words. As a result, the series is known for its ambivalence, since children and adults alike can enjoy it for different reasons. Keeping these facts in mind, this research aims at using today's linguistic theories and looking at word creation in both English and French in order to establish patterns of translation, and suggest possible equivalents for some of J. K. Rowling's inventions.

An interesting aspect of translation is the comparison of which grammatical constructs are common in one language but quite rare in the other. One such example is the act of verbalizing - that is to say turning a noun into a verb - which is extremely prevalent in English, but remains fairly awkward in French. People readily friend others on social networks, google information, or text family members. In French however, these verbs must be rendered as "ajouter un ami" ("to add a friend"), "rechercher sur Google" ("look up on Google") and "envoyer un texto" ("send a text message"). By looking at three examples, we can already see a pattern emerging: verbalized nouns in English seem to be translated into French as compound expressions made out of a verb, a preposition and a noun. In 


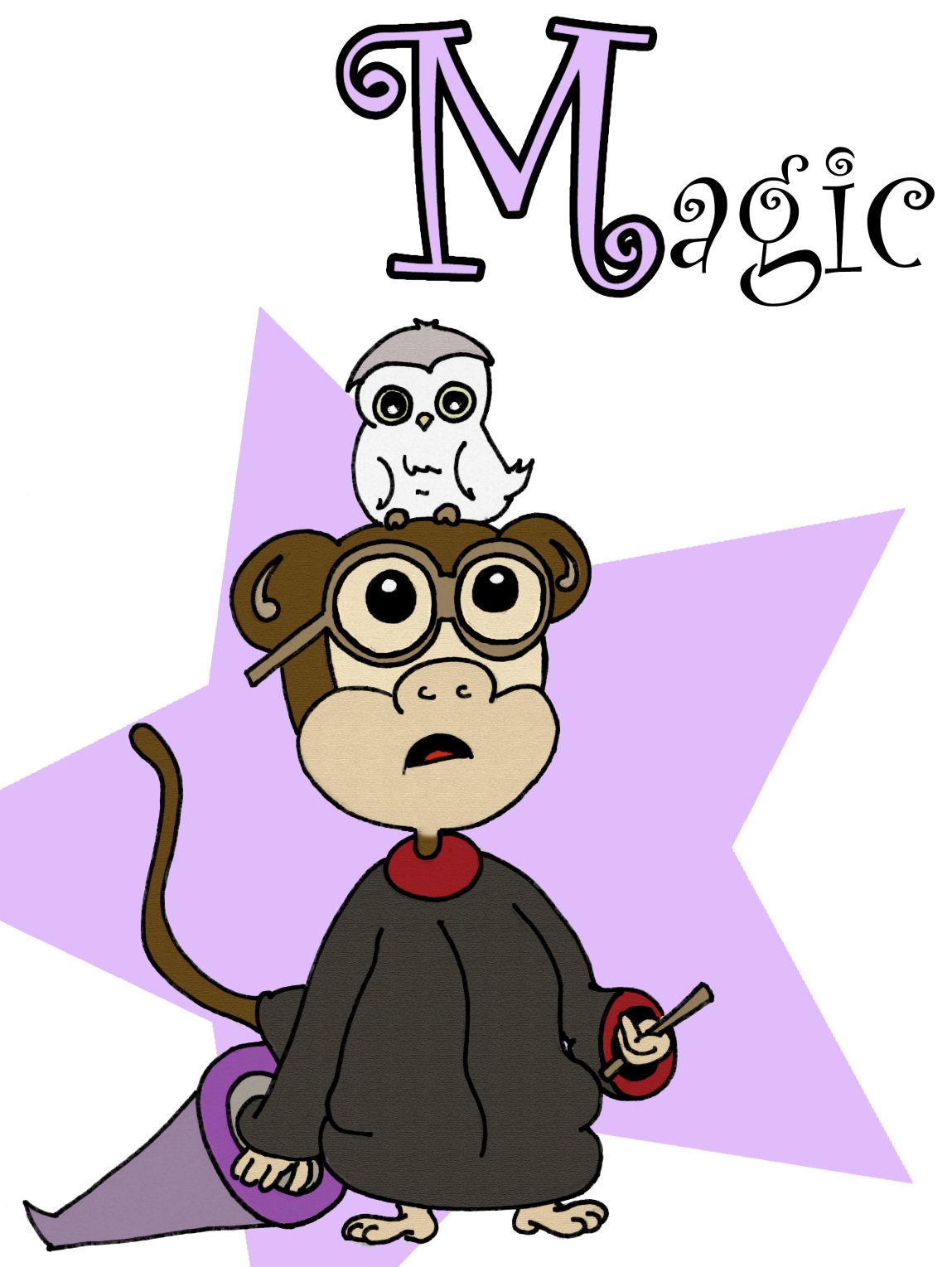


order to decide which words to analyze and translate in Harry Potter, I compiled a list of all of Rowling's lexical inventions, and categorized them based on the word-formation processes used by the author. Of the 450 -odd words she coined, almost $40 \%$ are compounds, making compounding the most popular word-formation process in the series. Strang (I970) describes it as the process by which "two or more words are combined into a morphological unit." The requirement that the components should be words does not rule out components which take on special forms in compounding (such as shepherd = sheep + herd,) but does exclude formations using morphemes, which operate only at a sub-word level (for example nano- in nanotechnology or sub- in subcategory).

The vast majority of compounds in English are constructed in such a way that the left-hand element modifies the right-hand element; such compounds exhibit what is called modifier-head structure. For instance, since the compound blackbird is a type of bird, modified by the adjective black, bird is the head of the compound while black is a modifier. Similarly, write is the head in the compound verb handwrite, and is modified by the noun hand. Plag (2003) explains that compounds have a very important systematic property because of their head: they inherit most of their semantic and syntactic information from it. If the head of a compound is a verb, the compound will usually be a verb (e.g. a breast + to feed = to breastfeed); if the head is a noun, the compound will usually be a noun (e.g. to swear $+a$ word $=a$ swearword). Most compounds in English are endocentric, that is to say, they describe a sub-category of the head element. For example, a grephound is a kind of hound, blood-red is a specific shade of red, and to handwrite is a particular way of writing. Therefore, endocentric compounds are hyponyms of the head. In comparison, some compounds are exocentric, that is they do not refer to a specific kind of what the head element refers to. For example, a white-collar is neither white nor is it a collar.

Studies show that compounding is among the earliest derivational processes used by children, and it has been on the increase since at least I970 according to scholars such as Arnaud (2003). Indeed, in many languages, compounding is the main way of creating new words. Since English is mostly an analytic language, unlike most other Germanic languages, it creates compounds by joining words without case markers. In Germanic languages, compounds may be arbitrarily long. However, this is obscured by the fact that the written representation of long compounds very often contains a space between the elements of the compound (such as assistant manager). Compounds do not always appear is such an obvious form as blackbird, but instead can be written in three different ways:

[I] The first form is the solid or closed form in which two moderately short words appear together as one. Solid compounds usually consist of short monosyllabic units that have often been established in the language for a long time. Examples include housewife, underworld, and sleepwalk.

[2] The second possible form for compounds in English is the hyphenated form, in which two or more words are connected by a hyphen. Compounds that contain affixes, such as house-build(er) and singleminded(ness), as well as compounds made up of two adjectives or two verbs, such as blue-green and freeze-dry, are often hyphenated. Compounds that contain grammatical words (i.e. prepositions or conjunctions) such as mother-of-pearl, salt-and-pepper and mother-in-law, are also usually hyphenated. 
[3] The open or spaced form is the last form compounds can take in English. It consists of newer combinations of somewhat longer words, such as distance learning, smoke screen, or tennis lawn. It can be difficult to differentiate open compounds from otherwise ordinary words put together in a sentence; what makes them compounds is the fact that they function as a single lexical unit whose parts cannot be separated without losing semantic information.

It is important to note that written usage in the United States and the United Kingdom differs and often depends on the individual choice of the writer rather than on a hard-and-fast rule. Open, hyphenated, and solid forms may therefore be encountered for the same compound noun, such as the triplets container ship / container-ship / containership and particle board / particle-board / particleboard. Hughes (1939) further explains that the historical development of compounding tends to evolve from an open form to a hyphenated one, and eventually change into a solid form. Indeed, words first appear as separate units, but after being used together in language over a period of time, acquire additional lexical information and become compounds.

In French, compounds - known as 'mots composés' - are created by placing two or more lexemes side by side to create a new one, very much like in English. The new lexeme is a unit on a semantic and syntactic level, but a few differences can be observed in French, especially when it comes to how the written form. For example, the adverb 'tout à fait' is made up of three words but represents one lexeme. Unlike English, which only has three different forms of compounds, four kinds of 'composés' can be observed:

[I] Composés unifiés are the most similar to English compounds since the elements they are made up of are placed side by side, such as in portemanteau (coat rack).

[2] Composés à trait d'union are compounds whose elements are separated by a hyphen, in words such as après-midi (afternoon).

[3] Composés à apostrophe are compounds whose elements are separated by an apostrophe, for example entr'ouvert. The apostrophe often takes the place of a letter that has been dropped, such as the "E" in entr'ouvert (ajar) and presqu'ile (peninsula).

[4] Composés détachés look like different words on paper since their elements are separated by spaces (as well as a preposition such as de or $\grave{a}$ in some cases), but they work as a single syntactic and semantic unit (e.g. pomme de terre $=$ potato). As in English, it can be difficult to differentiate a composé détaché (or open compound) from a regular sequence of words. What makes pomme de terre a composé détaché is that the sequence of words means more than the sum of its parts, and it cannot be broken up into pieces. Indeed, the compound does not refer to an apple (pomme) or to the earth (terre) directly; rather the combination of lexemes allows the creation of a new meaningful unit.

When looking at compounds in English and French, I discovered that if solid compounds are the most common form in English, hyphenated and open compounds are more common in French. This fact will play an important part in translation, since what is "normal" or expected in one language might be surprising or awkward in the other. As there are many compounds, it is not always an easy task to classify them. Linguists and scholars usually do so by distinguishing them based on their 
word class as well as the word class of the elements that compose them. For example, the word blackbird is a noun but is also an "adjective-noun" compound. Pickpocket is an example of a verb-noun compound. Most of Rowling's compounds are in solid form rather than being hyphenated or open, and a vast majority of them are noun-noun compounds (44\%), adjective-noun (22\%) and noun-verb (I7\%). It should be noted that the most common creative compounds in Harry Potter are also the most common in the English language, indicating that Rowling herself is still operating under a set of "rules".

The goal of this research is to focus on these three common types of compounds: noun-noun, adjective-noun and verb-noun compounds, establish patterns of translation based on the form these compounds take in French, and then apply these patterns to some of Rowling's creations.

When analyzing words that are compounds in both English and French, we immediately notice that English prefers solid compounds, whereas French seems to favor open or hyphenated compounds with prepositions. For example, words like stomachache, headache, toothache, etc. - are all translated into French as open compounds using the preposition de (mal de ventre, mal de tête, rage de dent). French also uses hyphenated noun-noun compounds where English often sticks to solid ones: for example, oiseau-mouche, oiseau-lyre, for hummingbird and lyrebird. nounverb compounds are the trickiest because (whether solid, hyphenated or open in English) they appear in French as complex compounds that make the meaning of the word more explicit. For example, handwrite becomes écrire à la main ("to write with one's hand"), card-index becomes mettre sur fichier ("to index on a card/file") and finger paint becomes peindre avec les doigts ("to paint with one's fingers").

We can also see a difference between English and French when looking at the head of the compound. As we have seen earlier, the head is usually placed second in English, but it is placed first in French. Indeed, bloodBATH becomes BAIN de sang and windMILL becomes MOULIN à vent, and if we look at adjective-noun compounds, we see the same pattern. A blackLIST is une LISTE noire, bareFOOT is PIEDS nus and a blackSMITH is un MARÉCHAL-ferrant. When using a noun-noun compound, this inversion does not affect the categorization of the compound, but with adjectivenoun or verb-noun compounds, we can see that they become NounAdjective or noun-verb compounds in French. For adjective-nouns, this mirrors the fact that adjectives in English are usually placed in front of nouns (e.g. a black cat) whereas they usually come after in French (e.g. un chat noir).

Therefore, when translating compounds from English into French, we must remember these two major differences. The goal of this research is to focus on the translation of the meaning of selected compounds, sometimes at the cost of sounds. Although its musicality has a great importance in the impact of a foreign word on the reader, it is through the meaning and the references that the purpose of the author is revealed. Rowling sometimes uses the properties of compounds to give clues (or red herrings), or simply to be economic with descriptions.

In order to attempt to translate her invented lexicon, it is important to research what the author's intentions were when she created with each word or name. The Harry Potter Lexicon, as well as a number of other online websites, gathers information Rowling gave about the hidden 
meaning of the words she invented. Whether she combines words to create new ones, modifies the name of a legendary creature to create her own beast, or simply reinstates an old word after a slight change, the author of the series is well known for the witty way in which she uses these methods. We also need to keep in mind that some of the words Rowling creates are characters' last names, and can therefore not appear in open form, either in English or French.

When dealing with translation, it is useful to use John Taylor's (2002) definition of a domain. He explains that a domain is a "background knowledge configuration against which conceptualization is achieved." In other words, every lexeme refers to something bigger that encompasses it, a reference people need to understand in order to grasp the full meaning of the word. For example, in the case of the word hypotenuse, Taylor points out that we need "background knowledge" of planar geometry - or space even - in order to understand the concept of the word. In this example, planar geometry constitutes the domain against which triangles and their properties are conceptualized - it provides the context (Taylor's concept of domains is close to Croft and Cruse's (2004) account of the concept of frames originally developed by Fillmore \& Kay). Moreover, Taylor explains that domains often overlap and interact, since words are described and conceptualized in more than one way. He quotes Langacker (I987) who refers to the set of domains necessary to the full understanding of a word as a "matrix". Establishing the domain of a word is extremely relevant when dealing with translation, since it allows us to determine the author's intent as well as the wealth of ideas created by a word in the reader's mind. In the case of Rowling's lexical inventions, this allows the translator to compile a list of meanings and ideas that need to be rendered, but also establishes words as matrixes. As a result, the translator is able to search for different possible translations - not necessarily literal - which will have the same effect on the audience as the original compound. Without a domain, the meaning of a word - especially a lexical invention - can be ambiguous. For example, Rowling created a creature called "ashwinder," and we can notice that the second part of the compound can be read as [windər] or [waindər]. In that case, using the compound as a matrix and establishing a domain of meanings can help us pick out its correct reading. With words such as snake, vine and ensnare, we can determine that the word is pronounced [æ\waindər] after to wind meaning to coil, to bend, to wrap.

We have therefore established two patterns of translation between English and French. First, we know that although solid compounds are the most common type in English, French favors open or hyphenated forms. Moreover, elements in an English compound tend to be inverted once translated into French. With these tendencies in mind, as well as Taylor's (2002) concept of domain, the next section will present three of Rowling's creative compounds and suggest a possible French translation for them. A comparison to the official French translation by Jean-François Ménard will also be presented.

The first word to be analyzed is "fiendfyre" which describes a powerful fire spell that usually takes the shape of fiery beasts, like serpents, dragons, and birds of prey. Fiendfyre is a solid noun-noun compound in English, a category that usually appears as open or hyphenated N-N 
compounds in French, possibly with a preposition like de or à. There are two significant elements in the compound "fiendfyre": the alliteration created by the [f] sound, but more importantly the semantic frame of the word - that of danger and destructiveness. The domain created by the lexeme fiend includes monsters, and in a broader sense, all creatures with menacing teeth, especially large ones like dragons. Using the example of other French compounds such as Dent-de-Lion (Dandelion, lit. "Lion Tooth") or Dent-de-Sabre (Sabertooth [tiger]), I was able to create the compound "Dents-de-Feu" (Fire Teeth), simultaneously maintaining the domains of fire and dangerous creatures. Moreover, alliteration is created by the repetition of the [d] sound which perpetuates the spell-like quality of the compound.

The official French translation of Fiendfyre - "Feudeymon" focuses on the demonic meaning of fiend, by combining démon (demon) with the word feu (fire). The spelling of the lexeme is altered into "deymon" in order to mimic the change in spelling of "fyre" in "fiendfyre" and reinforce its magical qualities. The compound appears in solid form, which is rare in French as we have seen, but is acceptable due to it being a spell.

The second compound to be analyzed is the name of Harry Potter's school, "Hogwarts." The semantic domains created by this name are of conflicting visions of ugliness and magic, because it can be separated into the words hog and warts. Since the compound is a proper name, it should appear in solid form even when translated into French. The words porc (pig, hog) and cloque (blister) - which belongs to the semantic frame of warts - are possible French translations for the two parts of "Hogwarts." Moreover, they allow the translator to use the compounding process to combine them through the letter ' $C$ ' to create "Porcloque," since it is the last letter of the word porc and the first letter of cloque. The downside of this translation is that it breaks the pattern of reversed elements in a compound in French.

The official translation of Hogwarts in French is "Poudlard," and it is probably the choice Ménard had to explain and comment on the most. Indeed, it appears very different from the original Hogwarts. The translator says he focused on the meanings of hog and warts, and used synonyms or words belonging to the same semantic domain to offer an equivalent. As a result, hog became lard (bacon, fat [of pig]) and warts became pou (louse/lice) - which remains within the semantic domain of viruses, parasites and infections. Ménard maintained the solid form necessary for a proper name.

The last example we will analyze is the word "Portkey." In the Harry Potter series, "Portkeys" are enchanted objects that can transport people to a faraway location. An interesting aspect of "portkey" is the fact that the name explains both the literal and symbolic meaning of the word. Indeed, "portkeys" act as portals to different locations, but they are often the key to a mystery or a predicament. These two aspects need to be maintained and communicated through the translation. By combining the words clé for key and port for port, we can create a compound like "Portclé." However, this creation sounds too much like the French word porte-clés meaning key ring, and the translator therefore needs to modify one of the lexemes. Extrapolating the idea of transport conveyed in the semantic domain of port, I was able to use the word expéditeur (shipper/sender), which is also close to the words expédition (expedition) and expédier (to send/to pack off). This allowed me to combine it with clé to create the compound 
"cléxpediteur." Here, the decision was made to step away from the science of translation and the pattern previously established, by choosing a solid compound over its open form, thus focusing on the artistic side of translation.

The official French translator used a similar process and produced "Portoloin," which resembles an onomatopoeic version of "porte au loin" (carries far away/door far away), and is reminiscent of Rowling's way of creating words. The word feels like it belongs in the lexicon created for the Harry Potter books, while conveying the ideas of travel and transportation inherent to the original "Portkey." The downside is that the idea of key literally or figuratively - is lost in translation.

As we have seen, the compounding process shows variations in English and French, but by looking at various fields involving compounds - such as morphology, grammar and lexicology - we can establish patterns of translation between the two languages. The trademarks of Rowling's style - allusions, anagrams, alliterations, references and other puns - can therefore be conveyed into French, especially since the patterns observed are relatively flexible. Translation is a science deeply rooted in human emotion, and therefore depends on the interpretation, style and point of view of translators. For that reason, studying the work of official French translator Jean-François Ménard, who did an admirable job, especially considering the time constraints he worked under, was truly fascinating. As we have seen, he took some liberties with his translations and the hidden meaning of words is sometimes lost, but this is greatly balanced by his humor, his wit and his obvious love of literature.

As a last word, I would like to invite anyone to try their hand at new translations since, despite being an emotional science, translation is also an evolving one. With new words - and compounds - created every day, translators have more and more tools at their disposal to recreate the magic of Harry Potter.

\section{Works CiTED \\ Primary Sources}

Rowling, J.K. (I998). Harry Potter and the sorcerer's stone. Pittsburg: Scholastic, Arthur A. Levine Books.

---. Harry Potter à l'école des sorciers. (I998). Trans. Jean-François Ménard. Paris: Gallimard.

---. Harry Potter and the goblet of fire. (2000). Pittsburg: Scholastic, Arthur A. Levine Books.

---. Harry Potter et la coupe de feu. (2000). Trans. Jean-François Ménard. Paris: Gallimard.

---. Fantastic beasts and where to find them. (2001). Pittsburg: Scholastic, Arthur A. Levine Book.

---. Harry Potter and the deathly hallows. (2007). Pittsburg: Scholastic, Arthur A. Levine Books.

---. Harry Potter et les reliques de la mort. (2007). Trans. Jean-François Ménard. Paris: Gallimard. 


\section{Secondary Sources}

Arnaud, Pierre J.L. (2003). Les composés timbre-poste. Lyon : Presses Universitaires.

Croft, William and D. Alan Cruse. (2004). Cognitive linguistics. Cambridge: Cambridge University Press.

Hughes, Geoffrey. (I939). A history of English words. Oxford and Malden: Blackwell Publishers.

Langacker, Ronald W. (1987). Foundations of cognitive grammar, vol. I: theoretical prerequisites. Stanford, CA: Stanford University Press.

Plag, Ingo. (2003). Word-formation in English. Cambridge: Cambridge University Press.

Strang, Barbara M.H. (1970). A history of English. London: Methuen \& Co Ltd.

Taylor, John R. (2002). Cognitive grammar. Oxford: Oxford University Press.

Dictionaries

Larousse / Chambers. Paris. Larousse /HER, I999.

Oxford advanced learner's dictionary. Oxford University Press, 1948.

Petit Larousse illustré, le. Paris: Larousse, I905.

Websites

Harry Potter lexicon, the. 2000. <www.hp-lexicon.org> 